\title{
ANÁLISE DAS DESIGUALDADES SALARIAIS ENTRE HOMENS E MULHERES NO MERCADO DE TRABALHO DE SANTA CATARINA
}

Taise Fátima Mattei ${ }^{1}$

Fernanda Mendes Bezerra Baço²

\begin{abstract}
RESUMO
O mercado de trabalho é marcado por elevadas desigualdades salariais entre homens e mulheres. Partindo desse contexto, o objetivo desta pesquisa é explicar as diferenças salariais existentes no mercado de trabalho do estado de Santa Catarina nos anos 2000, 2007 e 2014 com base nas teorias que buscam explicar as desigualdades salariais. Para esta finalidade, serão estimadas equações Mincerianas de salários e utilizado o método de decomposição de rendimentos de Oaxaca-Blinder. Os dados utilizados na pesquisa são provenientes da RAIS. Os principais resultados revelaram que as diferenças salariais, em termos percentuais, entre homens e mulheres, diminuíram no período analisado no estado. No mesmo sentido, a discriminação salarial contra as mulheres também diminuiu no período, sendo, no entanto, o principal componente a explicar as diferenças salariais entre homens e mulheres. Dessa forma, sugere-se a necessidade de que se desenvolvam políticas voltadas ao combate da discriminação no mercado de trabalho, buscando, assim, diminuir as desigualdades salariais.
\end{abstract}

Palavras-chave: Capital Humano. Desenvolvimento Regional. Discriminação. Segmentação.

\section{ANALYSIS OF SALARY INEQUALITIES BETWEEN MEN AND WOMEN IN THE MARKET OF WORK OF SANTA CATARINA}

\begin{abstract}
The labor market is marked by high pay inequalities between men and women. From this context, the objective of this research is to explain the wage differences existing in the labor market of the state of Santa Catarina in the years 2000, 2007 and 2014 based on theories that seek to explain wage inequalities. For this purpose, Mincerian wage equations will be estimated and the Oaxaca-Blinder yield decomposition method will be used. The data used in the survey come from RAIS. The main results revealed that the wage differences, in percentage terms, between men and women, decreased in the period analyzed in the state. Similarly, wage discrimination against women also declined in the period, but it is the main component of wage differentials between men and women. Thus, it is suggested that policies aimed at combating discrimination in the labor market should be developed, thus seeking to reduce wage inequalities.
\end{abstract}

Keyworks: Human capital. Regional Development. Discrimination. Segmentation.

\footnotetext{
${ }^{1}$ Mestre em Gestão e Desenvolvimento Regional. Professora na Unioeste. Francisco Beltrão, PR. Brasil. E-mail: taise mattei_slo@hotmail.com

${ }^{2}$ Doutora em Economia. Professora na Unioeste. Francisco Beltrão, PR. Brasil. E-mail: ferpompeia@gmail.com
}

DRd - Desenvolvimento Regional em debate (ISSNe 2237-9029)

v. 7, n. 2, p. 96-117, jul./dez. 2017. 


\section{INTRODUÇÃO}

O Brasil pode ser caracterizado como um país de grandes desigualdades econômicas e sociais, tanto entre as pessoas, como também entre regiões. Muitos fatos podem explicar essas desigualdades, desde o formato que se deu a colonização até a formação e consolidação da estrutura produtiva.

Ferreira et al. (2006) apontam que, aproximadamente, entre as décadas de 1960 e meados da década de 1970, houve elevação das desigualdades de renda no Brasil. De meados da década de 1970 até o início da década de 1980 houve um movimento inverso. E novamente, a partir desse período até o início da década de 1990, as desigualdades se elevaram e estiveram intimamente ligadas ao processo de aceleração da inflação somado ao baixo crescimento da educação e da força de trabalho.

O Brasil passou por grandes transformações econômicas e institucionais que levaram a estabilização da economia e diminuição das desigualdades sociais e econômicas, principalmente após o Plano Real (BESSA, 2013). Ferreira et al. (2006) constataram que houve, no início da década de 1990, várias oscilações das desigualdades, principalmente de rendimentos, até que se iniciou um processo mais contínuo de redução dessas diferenças. No entanto, Bessa (2013) argumenta que somente na primeira década do século XXI é que os valores das desigualdades sociais no Brasil declinaram de maneira acentuada. Apesar disso, mesmo que os indicadores de concentração de renda e de desigualdades sociais tenham melhorado, o Brasil ainda possui como característica marcante o elevado grau de desigualdade (FERREIRA et al., 2006).

Ao analisar o mercado de trabalho, é possível observar que também existem disparidades por gênero, tanto entre as ocupações, quanto em relação às remunerações. As desigualdades existentes no mercado de trabalho por gênero podem impactar negativamente na condição de vida das pessoas e na eficiência da economia, contribuindo para aumentar a pobreza e as desigualdades sociais. Diante deste contexto, estudar as causas dessas desigualdades, principalmente salariais, é um tema relevante para a realidade brasileira. Esse estudo é possível por meio do mercado de trabalho, pois ele possibilita a análise e medição das desigualdades através da análise das remunerações.

No presente trabalho serão abordadas as desigualdades salariais por gênero no estado de Santa Catarina. A escolha desse estado se justifica por pertencer a uma região bastante desenvolvida do Brasil e apresentar elevadas desigualdades salariais entre homens e mulheres.

As desigualdades salariais entre homens e mulheres, no Brasil, e nos estados da Região Sul, podem ser verificadas por meio da análise dos salários médios. Segundo a RAIS (BRASIL, 2016), a remuneração média medida em reais, em 2014, para o homem no estado de Santa Catarina era de $\mathrm{R} \$ 2.534,62$, já para a mulher era de $\mathrm{R} \$ 2.005,95$. As mulheres recebiam salários médios menores e essas diferenças necessitam ser explicadas de alguma forma. À primeira vista, é tentador atribuir toda a diferença salarial à existência de discriminação. No entanto, outros fatores podem influenciar em tais diferenças, como por exemplo: diferenças de escolaridade, disponibilidade de horas para trabalhar, diferenças de inserção no mercado, entre outras. 
Uma discussão a respeito do diferencial de salários, abordagem principal dessa pesquisa, precisa levar em conta os possíveis determinantes. Fiuza-Moura (2015) destaca que diversas teorias recentes tentam explicar as diferenças salariais no mercado de trabalho. As principais são: teoria do capital humano, da segmentação e da discriminação. Tais teorias sugerem que essas diferenças podem surgir devido a alguns fatores: diferenças de escolaridade e experiência; diferenças de ocupações, regiões geográficas, cargos, entre outros; e fatores não-produtivos como sexo, cor, religião, entre outros.

Neste contexto, partindo da ideia que existem diferenças salariais entre homens e mulheres no mercado de trabalho, e baseando-se nas teorias que podem explicar as diferenças salariais, o problema da pesquisa é: como são explicadas as diferenças salariais entre homens e mulheres no mercado de trabalho do estado de Santa Catarina nos anos de 2000, 2007 e 2014, a partir da aplicação das teorias de desigualdades salariais?

Assim, o objetivo geral deste trabalho é explicar as diferenças salariais existentes no mercado de trabalho do estado de Santa Catarina nos anos 2000, 2007 e 2014, com base nas teorias que buscam explicar as desigualdades salariais. Ou seja, busca-se analisar quais teorias que explicam as desigualdades salariais podem contribuir para explicar as diferenças salariais no mercado de trabalho do estado nesse período.

É importante identificar o que elucida as diferenças salariais por gênero, para que possam ser criadas e implementadas políticas e ações para combatê-las. Além disso, diminuir as desigualdades salariais pode ser importante para a redução da pobreza, melhoria do bemestar da população e igualdade entre as pessoas.

O estudo das desigualdades salariais no Brasil é relevante devido à elevada concentração de renda e grande diversidade de qualidade da força de trabalho, pois contribuem para elevar essas disparidades. Da mesma forma, é necessário conhecer os grupos que são prejudicados com a subtração de seus rendimentos e, assim, aumentar os conhecimentos sobre o mundo do trabalho, principalmente com relação à atividade feminina, que teve historicamente maiores dificuldades de inserção e menores remunerações.

Além disso, a Constituição Federal do Brasil (BRASIL, 1988), quando fala dos direitos e deveres fundamentais dos indivíduos no artigo $5^{\circ}$, mostra que homens e mulheres devem ser tratados igualmente, tanto em relação aos direitos como em obrigações. Quando se refere aos direitos sociais, no artigo $6^{\circ}$, assinala que são proibidos tanto diferença salarial, quanto exercício de função e critérios de admissão entre pessoas em função de sexo, idade, cor ou estado civil. Esses dois dispositivos legais deixam evidente que é proibido qualquer tipo de discriminação no Brasil, seja ela de cor, sexo, idade, entre outras, além de garantir o tratamento igualitário para homens e mulheres.

A participação da mulher no mercado de trabalho e as diferenças de rendimentos, principalmente salariais e por gênero, vêm sendo objeto de inúmeros estudos. É um assunto muito discutido e debatido na literatura brasileira e também mundial. Apesar de a lista de trabalhos que analisam o diferencial de salários por gênero ser extensa, existe uma lacuna nos estudos que analisam a evolução das diferenças ao longo de um período, por isso essa pesquisa se justifica também nesse sentido.

A referida pesquisa tem caráter quantitativo e será desenvolvida com base nos microdados da RAIS- Relação Anual de Informações Sociais, fornecidos pelo Ministério do 
Trabalho e do Emprego, para os anos de 2000, 2007 e 2014. A base de dados da RAIS foi escolhida por ser uma pesquisa que estuda exclusivamente o mercado formal de trabalho, de forma quase censitária, além de ser um diferencial da pesquisa, já que a maioria dos trabalhos nessa área utiliza a PNAD. O ano de 2014 foi escolhido com base na disponibilidade de dados, e os anos de 2000 e 2007 como sendo um intervalo considerável para a análise da evolução das desigualdades salariais. A amostra vai corresponder as informações declaradas na RAIS pelas entidades empresariais dos estados da Região Sul do Brasil.

Para a obtenção dos resultados foram estimadas equações Mincerianas de salários para homens e mulheres no mercado de trabalho e após isso, foi aplicado o método de decomposição de rendimentos de Oaxaca-Blinder que serve para decompor as diferenças salariais e verificar o impacto atribuído às características observáveis, capital humano e a segmentação, e às características não observáveis, discriminação salarial.

Este trabalho está organizado da seguinte forma, além desta introdução: a seção 2 traz o referencial teórico utilizado; na seção 3 é mostrado a metodologia a ser empregada; na 4 são apresentados os resultados e discussões; e por fim, na seção 5 , as considerações finais da pesquisa.

\section{REFERENCIAL TEÓRICO}

Esta seção aborda, inicialmente, as teorias que buscam explicar as desigualdades salariais descritas pela literatura. Ramos e Vieira (2001) apontam quatro fatores que buscam explicar as diferenças salariais dos participantes do mercado de trabalho: a primeira teoria ele chama de diferenciais compensatórios, que são os ganhos a mais por trabalhos que requerem maiores riscos, insalubridades, entre outros; a segunda teoria refere-se às diferenças de atributos produtivos dos trabalhadores, ou seja, diferenças de capital humano, como educação, experiência, entre outros; a terceira indica as diferenças salariais provenientes da segmentação no mercado, em que os trabalhadores são igualmente produtivos, mas recebem remunerações diferentes devido à forma como são inseridos, muitas vezes baseadas nas diferenças regionais, setoriais; e a última refere-se à discriminação salarial, em que o mercado remunera os participantes baseado em atributos não produtivos, como cor, sexo, etc.

Neste trabalho são adotadas apenas três das teorias que podem explicar as diferenças salariais, sendo elas: capital humano, segmentação e discriminação. A exclusão dos "diferenciais compensatórios" dá-se pela dificuldade em se determinar variáveis que possam captar esses efeitos, visto que o banco de dados utilizado também tem dificuldades em apresentar variáveis que sejam úteis para determinar os efeitos desses diferenciais compensatórios.

Dessa forma, a seguir, são apresentadas, detalhadamente, as três teorias que buscam explicar as desigualdades salariais utilizadas como base para a explicação das diferenças salariais no mercado de trabalho dos estados da Região Sul do Brasil.

DRd - Desenvolvimento Regional em debate (ISSNe 2237-9029) 


\subsection{TEORIA DO CAPITAL HUMANO}

Segundo Schultz (1961), capital humano refere-se a um estoque de habilidades e conhecimentos interiorizado na pessoa, capaz de gerar maior renda e produto, pois possibilita melhorar a sua produtividade. Becker (1962) relata que para a teoria do capital humano, conforme aumenta o nível de educação de uma pessoa, aumenta também a sua renda, porque ela está inserida dentro das premissas neoclássicas que assumem que os fatores são remunerados de acordo com sua produtividade.

Para Schultz (1961), quando uma pessoa utiliza parte do seu tempo de lazer para melhorar suas habilidades e conhecimentos, está investindo em capital humano. Além disso, ele aponta que pessoas mais escolarizadas e treinadas tendem a receber salários maiores, pois são mais produtivas que outros que não investem em educação e treinamento. Ainda segundo Schultz (1961), a teoria do capital humano é na verdade uma teoria de investimento ou acumulação de capital na própria pessoa, e esse capital acumulado refere-se à educação, treinamento, experiência profissional, cuidado com a saúde, entre outros.

Becker (1962) relata que os diferentes investimentos em capital humano podem ser úteis para tentar explicar as diferenças de remunerações entre as pessoas. No mesmo sentido, Cirino (2008) aponta que a teoria do capital humano também se aplica para explicar as diferenças de remunerações entre homens e mulheres, buscando determinar porque os salários das mulheres são, muitas vezes, inferiores aos dos homens. Becker (1962) afirma que as mulheres podem possuir menores incentivos ao investimento em capital humano, pois historicamente apresentaram menores participações no mercado de trabalho. Cirino (2008) complementa que maiores descontinuidades devido ao cuidado com os filhos e atividade doméstica, também podem influenciar na decisão das mulheres de investir em capital humano. Isso pode fazer com que elas tenham menores experiências no trabalho, e, dessa forma, menor produtividade e menores salários. No entanto, Cirino (2008) também faz considerações no sentido de que a mulher está sendo inserida cada vez mais no mercado de trabalho e as desigualdades salariais estão reduzindo.

Schultz (1961) afirma que as diferenças de rendimentos estão estritamente relacionadas com os diferenciais na educação, nas qualificações e nas condições de saúde. Barros, Henriques e Mendonça (2002) relatam que quanto maior forem as diferenças de educação entre as pessoas, tende a ser o nível de desigualdades salariais existentes. As diferenças de remunerações dependem também de como o mercado de trabalho valoriza, em termos monetários, os anos adicionais de escolaridade das pessoas, sendo que, quanto maior for o valor associado aos anos de estudos adicionais, maior serão as desigualdades salariais.

Embora não seja a única a tentar explicar as causas das diferenças salariais, a teoria do capital humano busca em variáveis como escolaridade e experiência do trabalhador, um fator determinante para as desigualdades salariais existentes no mercado de trabalho. Devido a isso, é uma das teorias utilizadas para a explicação das diferenças salariais. Variáveis como tempo de emprego e escolaridade são utilizadas para tentar captar os efeitos do capital humano sobre os salários dos trabalhadores. 


\subsection{TEORIA DA SEGMENTAÇÃO}

Lima (1980) mostra que, no fim da década de 1960 e início de 1970, muitas críticas começaram a surgir em relação a teoria do capital humano, mesmo sem nenhuma nova teoria surgir em oposição. No entanto, na década de 1980, começou a ganhar forma uma teoria nova buscando complementar a de capital humano, e explicar a dualidade nos mercados de trabalho, a teoria da segmentação.

Para Fernandes (2002) a segmentação no mercado de trabalho refere-se aos mercados separados ou distintos, ou ainda a um conjunto de modelos e teorias que tratam do funcionamento do mercado de trabalho. Satel (2011, p. 20) comenta que "a teoria da segmentação está relacionada à concentração de trabalhadores em determinado mercado ou ocupação". Vários fatores têm sido usados como forma de segmentação, como: regiões geográficas, setores, ramos industriais, características demográficas, sindicalizações, regulamentação do mercado, entre outras (ARBACHE; NEGRI, 2002; FERNANDES, 2002).

Fernandes (2002) relata que diferenças salariais podem existir nos distintos segmentos do mercado, ocorrendo, assim, devido aos custos de mobilidade ou por características não pecuniárias dos postos de trabalho dos diferentes segmentos. Para Lima (1980), quando uma pessoa é alocada em um determinado segmento no mercado de trabalho, seu salário vai depender das regras internas daquele segmento com relação ao padrão salarial imposto e não das habilidades cognitivas, nem da produtividade do trabalhador, conforme prevê a teoria do capital humano.

Satel (2011) apresenta uma diferenciação entre a teoria da segmentação e a do capital humano. Enquanto a teoria da segmentação remunera um indivíduo de acordo com a ocupação ou setor em que está inserido, a teoria do capital humano remunera conforme a produtividade de uma pessoa no trabalho.

Arbache e Negri (2002) relatam que, em décadas recentes, a teoria da segmentação tem sido muito utilizada para explicar a dispersão e a estrutura de salários no mercado de trabalho. Tem sido muito usada como alternativa às ideias neoclássicas, ou seja, os neoclássicos enfatizam como explicação das desigualdades salariais o papel do capital humano. Os teóricos da segmentação criticam essa ideia e apontam a segmentação também como causa das desigualdades salariais. Fernandes (2002) aponta que essa literatura da segmentação apresenta ideias heterogêneas e amplas, sendo que o principal ponto de convergência entre os autores é o posicionamento de todos quanto à crítica à teoria neoclássica.

Portanto, a teoria da segmentação, ao dar um papel fundamental para o mercado de trabalho, tenta explicar as causas das diferenças salariais pelas diferenças de segmentos que o trabalhador está inserido, que podem ser setores econômicos, regiões geográficas, entre outros. Neste sentido, essa pesquisa não se limitou apenas a explicar as diferenças salariais por meio da teoria do capital humano, por isso, a teoria da segmentação também foi uma das teorias utilizadas para a explicação das diferenças salariais. Variáveis como tipo do estabelecimento e setores econômicos são utilizadas para tentar captar os efeitos da segmentação sobre os salários dos trabalhadores. 


\subsection{TEORIA DA DISCRIMINAÇÃO}

Rocha e Pero (2007, p. 124) apontam que, para a teoria da discriminação, um indivíduo é discriminado "se o contratante levar em consideração na escolha do emprego e do salário não apenas aspectos objetivos, como sua produtividade, mas também aspectos subjetivos, como raça ou sexo". No mesmo sentido, Loureiro (2003) relata que a discriminação existe quando um grupo com características produtivas idênticas recebem salários diferenciados ou tratamento diferenciado devido a atributos como raça, sexo, cor, entre outros.

Yannoulas, (2002) aponta que existem três formas gerais de discriminação tanto no mercado de trabalho como em outras áreas: direta ou manifesta, indireta ou encoberta e a autodiscriminação. A direta refere-se às regras e códigos explícitos que existem para excluir explicitamente um grupo social, em função de sexo, gênero, raça, etnia, religião, idade, e outros aspectos. Essa forma tem a consequência de manter um grupo em situação de desvantagem em relação a outro. No entanto, com os avanços de leis e normas que proíbem qualquer forma de discriminação, essa forma não é tão recorrente como era em tempos passados. A discriminação indireta consiste em ideias e práticas que atuam na informalidade e que podem influenciar e gerar um comportamento discriminatório em relação às pessoas que possuem as mesmas condições apenas por suas atribuições de sexo, raça, religião, etc. Essa forma será a utilizada para a análise da pesquisa. Por fim, a terceira forma, chamada de autodiscriminação, é tida como mecanismos internos que refletem, muitas vezes, os desejos e motivações discriminatórias de algumas pessoas, sentidos e reprimidos internamente pela própria pessoa.

As principais consequências da discriminação, principalmente com relação à mulher, revelam-se em profissões e ocupações desprestigiadas e mal remuneradas, impedimentos de acesso aos postos de trabalho, dificuldades de ascensão profissional, assédios sexuais, entre outras (YANNOULAS, 2002).

A discriminação encontrada no mercado de trabalho com relação às mulheres ou negros, pode ainda ser classificada exclusivamente em quatro tipos, segundo Loureiro (2003): discriminação salarial, de emprego, de ocupação e de acesso ao capital humano. A discriminação salarial significa que mulheres ou negros recebem salários menores por trabalho igual aos dos homens e brancos. A discriminação de emprego ocorre quando mulheres e negros recebem menores oportunidades de trabalho do que homens e brancos. A discriminação de ocupação ocorre quando mulheres e negros ficam impedidos de ocupar certos empregos mesmo tendo as mesmas capacidades produtivas. Por fim, a discriminação de acesso ao capital humano ocorre quando grupos discriminados, como mulheres e negros, ficam mais restringidos de aumentarem suas qualificações e aperfeiçoarem seus conhecimentos, fruto de oportunidades desiguais no mercado de trabalho, ou seja, por estarem em determinadas ocupações menos especializadas, ficam restringidos de obter maior conhecimento e aperfeiçoamento no emprego.

Concluindo, a teoria da discriminação busca explicar as diferenças salariais, atribuindo papel determinante para as características individuais e subjetivas dos trabalhadores, como sexo, idade, cor, religião, entre outras. Dessa forma, este trabalho baseou-se também na teoria 
da discriminação para buscar explicar as diferenças salariais entre homens e mulheres no mercado de trabalho dos estados da Região Sul do Brasil.

Portanto, a explicação das diferenças salariais tem como base as três teorias que buscam explicar as desigualdades salariais: capital humano, segmentação e discriminação. A teoria do capital humano busca explicar as diferenças salariais entre homens e mulheres devido às diferenças de escolaridade que esses trabalhadores possam apresentar. A teoria da segmentação se propõe a explicar as diferenças salariais devido aos segmentos distintos do mercado que os homens e mulheres possam estar inseridos. E a teoria da discriminação serve de base para explicar as diferenças salariais não explicados pela teoria do capital humano nem pela segmentação, atribuídas às características subjetivas dos trabalhadores.

\section{METODOLOGIA}

Este estudo tem abordagem quantitativa caracterizada como descritiva. A base de dados utilizada para este estudo é a RAIS, desenvolvida pelo Ministério do Trabalho e Emprego. A base de dados da RAIS foi escolhida para ser um diferencial da pesquisa, já que a maioria dos trabalhos nessa área utilizam a PNAD. A RAIS utiliza informações apenas para o mercado formal de trabalho, portanto, só para pessoas que trabalham formalmente, com carteira de trabalho, além de considerar somente pessoas ocupadas no mercado de trabalho.

A amostra utilizada na pesquisa compreende às informações declaradas na RAIS somente pelas entidades empresariais para os anos de 2000, 2007 e 2014, para o estado de Santa Catarina. O ano de 2014 foi escolhido com base na disponibilidade de dados da RAIS, sendo os dados mais recentes disponíveis. Os demais anos, 2000 e 2007, foram escolhidos como sendo um intervalo considerável para a análise da evolução das desigualdades salariais.

A categoria de entidades empresariais engloba: empresa pública, sociedade de economia mista, sociedade anônima aberta, fechada, limitada, empresário (individual), cooperativa, entre outras. As informações declaradas pelos empregadores são referentes a cada indivíduo empregado em entidades empresariais.

Dessa forma, a amostra da pesquisa contém as observações conforme a Tabela 1.

Tabela 1 - Amostra da pesquisa: número de observações declaradas pelas entidades empresariais

\begin{tabular}{l|c|c|c}
\hline Sexo/anos & $\mathbf{2 0 0 0}$ & $\mathbf{2 0 0 7}$ & $\mathbf{2 0 1 4}$ \\
\hline Masculino & 859.837 & 1.346 .167 & 1.834 .539 \\
\hline Feminino & 431.679 & 818.533 & 1.285 .627 \\
\hline Total & 1.291 .516 & 2.164 .700 & 3.120 .166 \\
\hline
\end{tabular}

Fonte: Elaborada pela autora, com base nos dados da RAIS (2016). 
Após a coleta dos dados e a organização deles no software STATA 12, serão feitos os procedimentos que serão detalhados a seguir. Contudo, estes procedimentos são calculados pelo software utilizado a partir de comandos específicos.

\subsection{EQUAÇÃO MINCERIANA}

Segundo Satel (2011), Mincer foi um dos primeiros formuladores da teoria do capital humano. Ele desenvolveu uma equação, chamada de equação Minceriana, em que tentou medir o quanto cada ano de estudo e experiência contribuía nos salários. Segundo Margonato (2011, p. 32) "a equação Minceriana de determinação de salários é a base para uma enorme literatura empírica e também o arcabouço utilizado para estimar retornos da educação, retornos da qualidade da educação, retornos da experiência, entre outros".

Neste trabalho, a equação Minceriana a ser determinada para o mercado de trabalho de cada estado, incluirá variáveis que tentarão captar os efeitos do capital humano (escolaridade, experiência, experiência ${ }^{2}$ ) e os efeitos da segmentação do mercado (CNPJ e setores econômicos) sobre os salários, objetivando estimar os salários de homens e mulheres, conforme a Equação 1. Nesta equação estão omitidas as variáveis do nível de escolaridade "analfabetismo" e do setor de "recursos naturais" para evitar multicolinearidade nos dados.

ln salário por hora: $\beta_{0}+\beta_{1}$ experiência $+\beta_{2}$ experiência ${ }^{2}+\beta_{3}$ até 5 anos inc. $+\beta_{4} 5$ anos comp. $+\beta_{5} 6$ a 9 anos fundamental $+\beta_{6}$ fundamental comp. $+\beta_{7}$ médio inc. $+\beta_{8}$ médio comp. $+\beta_{9}$ superior inc. $+\beta_{10}$ superior comp. $+\beta_{11}$ mestrado $+\beta_{12}$ doutorado $+\beta_{13}$ CNPJ $+\beta_{14}$ indústria $+\beta_{15}$ comércio $+\beta_{16}$ serviços $+\beta_{17}$ serviços domésticos $+\beta_{18}$ organismos internacionais $+\mu$

Após a determinação da equação Minceriana a ser estimada, inicia-se a decomposição de rendimentos de Oaxaca-Blinder.

\subsection{DECOMPOSIÇÃO DE OAXACA-BLINDER}

Segundo Jann (2008), uma metodologia muito usada na literatura para examinar a existência de discriminação salarial no mercado de trabalho entre grupos - seja ela discriminação por sexo, raça, entre outros - é a decomposição de Oaxaca (1973) e Blinder (1973). Essa metodologia divide o diferencial de salários entre dois grupos: uma parte explicada pelas características de produtividade (variáveis utilizadas para explicar os salários, sejam elas de capital humano ou segmentação) e uma parte residual, não explicada pelas diferenças de produtividade. A parte não explicada é utilizada como uma medida de discriminação, mas também refere-se às diferenças de preditores não observados pela estimação. Segundo Jann (2008), essa técnica pode ser usada com qualquer grupo de variáveis 
de resultado, podendo ser utilizada para medir desigualdades salariais, de saúde, educação, entre outras.

Segundo Satel (2011), estima-se dois modelos pelo método dos mínimos quadrados ordinários, conforme Equações 2 e 3:

$$
\begin{aligned}
& \ln \mathrm{Wm}=\alpha_{m}+\beta_{\mathrm{m}} \mathrm{X}_{\mathrm{m}}+\mu_{\mathrm{m}} \\
& \ln \mathrm{Wf}=\alpha_{f}+\beta_{\mathrm{f}} \mathrm{X}_{\mathrm{f}}+\mu_{\mathrm{f}}
\end{aligned}
$$

Em que: Wm refere-se a salário hora masculino; Wf refere-se a salário hora feminino; $\alpha$ é o intercepto da regressão; X é o vetor das características individuais e do mercado (idade, escolaridade, experiência, setores econômicos, regiões geográficas, etc); ln é o logaritmo do salário; $\beta$ é o vetor dos coeficientes; e $\mu$ é o erro do termo aleatório.

A partir das equações de salários são obtidos os valores médios e os parâmetros estimados, conforme as Equações 4 e 5.

$$
\begin{aligned}
& \overline{\ln W m}=\hat{\alpha}_{m}+\hat{\beta}_{\mathrm{m}} \bar{X}_{\mathrm{m}}+\mu_{\mathrm{m}} \\
& \overline{\ln W f}=\hat{\alpha}_{f}+\hat{\beta}_{\mathrm{f}} \bar{X}_{\mathrm{f}}+\mu_{\mathrm{f}}
\end{aligned}
$$

Segundo Jacinto (2005) e Margonato (2011), o diferencial de rendimentos pode ser calculado pela diferença entre as Equações 4 e 5, apresentado na Equação 6:

$$
\mathrm{D}=\overline{\ln W m}-\overline{\ln W f}=\left(\hat{\alpha}_{m}-\hat{\alpha}_{f}\right)+\hat{\beta}_{\mathrm{m}} \bar{X}_{\mathrm{m}}-\hat{\beta}_{\mathrm{f}} \bar{X}_{\mathrm{f}}
$$

Chaves (2011) relata que, somando-se e subtraindo-se a Equação 6 por uma média artificial dada pelo produto dos coeficientes da regressão das mulheres e a média da dotação dos atributos dos homens, $\hat{\beta}_{\mathrm{f}} \bar{X}_{\mathrm{m}}$, aplica-se a decomposição de Oaxaca e Blinder.

$$
\mathrm{D}=\overline{\ln W m}-\overline{\ln W f}=\left(\hat{\alpha}_{m}-\hat{\alpha}_{f}\right)+\hat{\beta}_{\mathrm{m}} \bar{X}_{\mathrm{m}}-\hat{\beta}_{\mathrm{f}} \bar{X}_{\mathrm{f}}+\hat{\beta}_{\mathrm{f}} \bar{X}_{\mathrm{m}}-\hat{\beta}_{\mathrm{f}} \bar{X}_{\mathrm{m}}
$$

Rearranjando tem-se:

$$
\mathrm{D}=\overline{\ln W m}-\overline{\ln W f}=\left(\hat{\alpha}_{m}-\hat{\alpha}_{f}\right)+\bar{X}_{\mathrm{m}}\left(\hat{\beta}_{\mathrm{m}}-\hat{\beta}_{\mathrm{f}}\right)+\hat{\beta}_{\mathrm{f}}\left(\bar{X}_{\mathrm{m}}-\bar{X}_{\mathrm{f}}\right)
$$

Segundo Jacinto (2005) e Chaves (2011), Oaxaca (1973) determinou a decomposição em apenas dois componentes. O termo da Equação 8, $\left(\hat{\alpha}_{m}-\hat{\alpha}_{f}\right)+\bar{X}_{\mathrm{m}}\left(\hat{\beta}_{\mathrm{m}}-\hat{\beta}_{\mathrm{f}}\right)$, representa a diferença salarial decorrente da discriminação contra o grupo em desvantagem, e refere-se ao fato de que pessoas com o mesmo nível de educação e experiência recebam salários diferenciados. Esse termo foi chamado de diferenças não explicadas. $O$ restante da Equação 8, o termo $\hat{\beta}_{\mathrm{f}}\left(\bar{X}_{\mathrm{m}}-\bar{X}_{\mathrm{f}}\right)$, se refere às diferenças salariais em decorrência das diferenças de características produtivas entre os trabalhadores, chamado de diferenças explicadas.

Fiuza-Moura (2015) relata que Blinder (1973) fez sua decomposição muito parecida com a de Oaxaca (1973), no entanto, dividiu em três componentes, ao considerar os 
interceptos das equações Mincerianas. O termo da Equação $8,\left(\hat{\alpha}_{m}-\hat{\alpha}_{f}\right)$, foi chamado de shift effect, e segundo Fiuza-Moura $(2015$, p. 41) "é a diferença observada nos salários única e exclusivamente devido ao fato de o indivíduo estar inserido no grupo em vantagem ou em desvantagem". Fiuza-Moura (2015) e Margonato (2011) mostraram que Blinder incluiu outro elemento nesse primeiro termo e chamou de interaction effect, $\left(\bar{X}_{\mathrm{m}}-\bar{X}_{\mathrm{f}}\right)\left(\hat{\alpha}_{m}-\hat{\alpha}_{f}\right)$, que segundo Margonato (2011), mede a interação entre os efeitos explicados e não explicados. No entanto, Fiuza-Moura $(2015$, p. 41) relata que esse termo não tem explicação econômica clara, mas pode "reduzir sub ou superestimações das partes explicadas pelas dotações ou pelos coeficientes". Para Jann $(2008$, p. 3), este termo "está representando um termo de interação para o fato de que as diferenças de dotações e coeficientes existem simultaneamente entre os dois grupos".

Segundo Margonato (2011), o outro termo da Equação $10, \bar{X}_{\mathrm{m}}\left(\hat{\beta}_{\mathrm{m}}-\hat{\beta}_{\mathrm{f}}\right)$, foi chamado de coefficient effect, o efeito não explicado pelos atributos produtivos. O último termo da Equação $8, \hat{\beta}_{\mathrm{f}}\left(\bar{X}_{\mathrm{m}}-\bar{X}_{\mathrm{f}}\right)$, foi chamado de endowment effect, o efeito explicado, obtido com as diferenças das médias dos atributos produtivos e forma de inserção dos trabalhadores.

Fiuza-Moura (2015) aponta que o método de Oaxaca que divide a decomposição em duas partes é chamado de twofold, e o método de Blinder que divide a decomposição em três partes é chamado de threefold. Neste trabalho, iremos utilizar a decomposição em três partes, dividindo as diferenças salariais em aspectos explicados pelas variáveis de capital humano e segmentação, em aspectos não explicados pelas variáveis utilizadas, sendo então atribuído à discriminação, e em aspectos de interação, que conforme já foi mencionado, não possui significado econômico claro.

Portanto, pode-se simplificar os procedimentos da seguinte forma: estima-se as equações Mincerianas de salários, e aplica-se a decomposição de Oaxaca-Blinder.

\subsubsection{Variáveis}

A variável dependente utilizada para determinar as equações Mincerianas de salários será a "remuneração média nominal por hora", transformada em logaritmo, conforme aponta a literatura. Para Carvalho, Neri e Silva (2006), como a jornada de trabalho de homens e mulheres pode ser diferente, é necessário calcular o diferencial de salários através de uma medida padronizada, sendo o salário/hora o salário recebido no mês dividido pela jornada de trabalho mensal.

Essa variável não consta no banco de dados da RAIS, no entanto, será obtida dividindo a "remuneração nominal média mensal" pela "quantidade de horas contratuais por mês". Consta no banco de dados da RAIS apenas a variável "quantidade de horas contratuais por semana", dessa forma, esses dados serão multiplicados por 4, assumindo que um mês possui em média, aproximadamente 4 semanas.

Os valores das remunerações dos anos de 2000 e 2007 foram deflacionados a preços de 2014 pelo INPC- Índice de Preços ao Consumidor, obtidos no IPEA-DATA. O INPC foi 
utilizado pois é um índice geral de preços e possuía seu valor para o período estudado. Dessa forma, será possível fazer comparações salariais entre os anos analisados, pois todos estarão na mesma base de preços.

As variáveis independentes utilizadas na pesquisa para estimar as equações de determinação de salários de homens e mulheres são divididas em dois blocos.

O primeiro bloco refere-se às variáveis que tentarão captar os efeitos do capital humano sobre as diferenças salariais. As variáveis apresentadas nesse bloco são: "experiência", "experiência ${ }^{2}$ " e os diversos níveis de escolaridade: "analfabetismo", "até 5 anos incompletos", "5 anos completos", "6 a 9 anos ensino fundamental", "fundamental completo", "médio incompleto", "médio completo", "superior incompleto", "superior completo", "mestrado" e "doutorado".

A variável "experiência", medida em anos, será utilizada para determinar o tempo de emprego do trabalhador. No banco de dados da RAIS, o tempo de emprego está medido em meses, sendo feito então a divisão por 12 para obter a variável em anos.

Será inserida a variável de interação "experiência a". Essa variável tentará captar o efeito dos rendimentos marginais decrescentes. Conforme explica a teoria do capital humano, a remuneração de um trabalhador aumenta conforme ele obtém mais experiência no mercado de trabalho, porém, conforme aumenta o nível de experiência de uma pessoa, os acréscimos nos rendimentos crescem, mas a taxas decrescentes. Ou seja, existem retornos marginais decrescentes: quanto mais experiência um trabalhador possuir, maior será a sua remuneração, no entanto, chega um momento da vida do trabalhador que o retorno sobre a experiência vai crescendo a taxas decrescentes.

O segundo bloco de variáveis tentará captar o fenômeno da segmentação no mercado de trabalho. Essas variáveis serão dummies, onde será atribuído 1 para a presença da característica da variável e 0 para a ausência. As variáveis de segmentação serão "CNPJ" e os diversos setores econômicos: recursos naturais, indústria, comércio, serviços, serviços domésticos, e organismos internacionais

A variável dummy "CNPJ", constante no banco de dados da RAIS, identificará se o estabelecimento é composto por empregador pessoa física (CEI-Cadastro específico do INSS) ou pessoa jurídica (CNPJ). A inclusão dessa variável permitirá observar se os salários variam conforme o tipo de estabelecimento do empregador, por isso está inserida no rol das variáveis de segmentação.

As variáveis categóricas para os setores de atividades econômicas identificarão o setor em que o trabalhador está inserido. A teoria da segmentação aponta que trabalhadores com a mesma produtividade recebem salários distintos em razão de empregos distintos, portanto, as variáveis categóricas para os setores econômicos permitirão verificar se existem diferenças de remunerações baseado no setor de atividade econômica.

$\mathrm{Na}$ especificação das equações Mincerianas para homens e mulheres, as variáveis "analfabetismo" e "recursos naturais" serão omitidas para evitar a multicolinearidade entre as variáveis, já que são variáveis dummy. 


\section{RESULTADOS E DISCUSSÕES}

Nesta seção serão apresentados os resultados da decomposição de Oaxaca-Blinder a partir das equações Mincerianas.

A Tabela 2 apresenta a decomposição salarial para o mercado de trabalho do estado de Santa Catarina nos anos 2000, 2007 e 2014.

Tabela 2 - Resultados da decomposição de salários no mercado de trabalho de Santa Catarina

\begin{tabular}{|c|c|c|c|c|c|c|c|c|c|}
\hline \multirow{2}{*}{ Santa Catarina } & \multicolumn{3}{|c|}{ Coeficientes 2000} & \multicolumn{3}{|c|}{ Coeficientes 2007} & \multicolumn{3}{|c|}{ Coeficientes 2014} \\
\hline & \multicolumn{2}{|c|}{$\ln$} & expo & \multicolumn{2}{|c|}{$\ln$} & expo & \multicolumn{2}{|c|}{$\ln$} & expo \\
\hline $\begin{array}{l}\text { Média salarial } \\
\text { homem }\end{array}$ & \multicolumn{2}{|c|}{1.8350} & $\mathrm{R} \$ 6.26$ & \multicolumn{2}{|c|}{1.9248} & $\mathrm{R} \$ 6.85$ & \multicolumn{2}{|c|}{2.1895} & $\mathrm{R} \$ 8.93$ \\
\hline $\begin{array}{l}\text { Média salarial } \\
\text { mulher }\end{array}$ & \multicolumn{2}{|c|}{1.6031} & $\mathrm{R} \$ 4.97$ & \multicolumn{2}{|c|}{1.6874} & $\mathrm{R} \$ 5.41$ & \multicolumn{2}{|c|}{1.9740} & $\mathrm{R} \$ 7.20$ \\
\hline $\begin{array}{l}\text { Diferença } \\
\text { salarial }\end{array}$ & \multicolumn{2}{|c|}{0.2319} & $\mathrm{R} \$ 1.30$ & \multicolumn{2}{|c|}{0.2373} & $\mathrm{R} \$ 1.45$ & \multicolumn{2}{|c|}{0.2155} & $\mathrm{R} \$ 1.73$ \\
\hline Componentes & $\ln$ & $\%$ rel. & \% impa. & $\ln$ & $\%$ rel. & $\%$ impa. & $\ln$ & $\%$ rel. & \% impa. \\
\hline Total explicado & -0.0253 & -10.92 & -2.50 & -0.0159 & -6.71 & -1.58 & -0.0242 & -11.23 & -2.39 \\
\hline Capital humano & -0.0154 & -6.65 & -1.53 & -0.0144 & -6.09 & -1.43 & -0.0189 & -8.78 & -1.87 \\
\hline Segmentação & -0.0099 & -4.27 & -0.98 & -0.0015 & -0.62 & -0.15 & -0.0053 & -2.45 & -0.53 \\
\hline $\begin{array}{l}\text { Total não } \\
\text { explicado- } \\
\text { discriminação }\end{array}$ & 0.2557 & 110.30 & 29.14 & 0.2464 & 103.83 & 27.94 & 0.2290 & 106.28 & 25.74 \\
\hline Total Interação & 0.0014 & 0.62 & 0.14 & 0.0068 & 2.88 & 0.69 & 0.0107 & 4.95 & 1.07 \\
\hline Total geral & 0.2319 & 100.00 & 26.09 & 0.2373 & 100.00 & 26.79 & 0.2155 & 100.00 & 24.05 \\
\hline
\end{tabular}

Fonte: Elaborada pela autora, com base nos dados da RAIS (2016).

Obs.: Valores percentuais do somatório dos componentes podem conter algumas diferenças em relação à soma total, devido à transformação do anti-logaritmo e devido aos arredondamentos.

$\mathrm{Na}$ parte superior da tabela, na primeira coluna, a primeira linha aponta a média salarial, por hora, dos homens, a segunda linha a média salarial, por hora, das mulheres, e a terceira linha a diferença salarial entre eles. Quando o valor é positivo, indica diferença salarial a favor dos homens. Esse valor é apresentado na escala logarítmica, pois a variável dependente utilizada é o logaritmo dos salários por hora.

A primeira coluna, na parte inferior da tabela, apresenta a decomposição dessa diferença salarial na forma logarítmica, indicando as parcelas referente ao capital humano, à segmentação, à discriminação e à interação, as quais podem contribuir para elevar ou diminuir as diferenças salariais a favor dos homens. Capital humano e segmentação pertencem ao componente explicado da decomposição, já discriminação pertence ao componente não explicado, pois refere-se às variáveis não consideradas no modelo. A parcela atribuída à interação, como já mencionado, não possui significado econômico claro, portanto, será excluída da análise quando forem feitas as interpretações dos resultados. 
A segunda coluna, na parte inferior da tabela, apresenta o percentual relativo das diferenças salariais que cada componente consegue explicar, bem como o total explicado pelas variáveis de capital humano e pela segmentação, o total não explicado por essas variáveis e atribuído à discriminação, e o total explicado pela interação entre os componentes. Quando o valor percentual relativo de um componente apresenta-se negativo, significa que ele não contribui para a explicação das diferenças salariais a favor dos homens, quando apresenta-se positivo, contribui para a explicação das diferenças salariais a favor dos homens, e, ainda, quando um valor ultrapassa $100 \%$, significa que toda diferença salarial foi explicada apenas por esse componente.

A segunda coluna, na parte superior da tabela, apresenta os valores da decomposição transformados na forma original, em reais, aplicando o inverso do logaritmo, isto é, na forma exponencial. A terceira coluna, na parte inferior, abaixo da forma expressa em reais, apresenta o percentual total das diferenças salariais, na forma exponencial, entre homens e mulheres, bem como o impacto percentual de cada componente, capital humano, segmentação, discriminação e interação, na diferença salarial. Se o sinal do componente explicativo "capital humano" for positivo, significa que esse componente contribuiu para aumentar as diferenças salariais a favor dos homens, ou seja, que os homens tiveram salário maior que as mulheres porque possuíam atributos de escolaridade ou experiência melhor que elas. No entanto, se esse componente apresentar um sinal negativo, significa que as variáveis de capital humano não contribuíram para elevar as diferenças salariais, mas sim, reduzi-las, pois, na verdade, eram as mulheres que possuíam os melhores atributos e deveriam receber incremento salarial. Da mesma forma, se o sinal do componente explicado "segmentação" apresentar sinal positivo, significa que contribuiu para elevar as diferenças salariais a favor dos homens, ou seja, as diferenças salariais foram atribuídas à existência de segmentação do mercado a favor dos homens. Contudo, se apresentar sinal negativo, significa que a segmentação não contribuía para elevar as diferenças salariais, mas sim, reduzi-las, pois, a segmentação, na verdade, era a favor das mulheres. Com relação ao componente "discriminação", se este apresentar sinal positivo, significa que as diferenças salariais a favor dos homens são também atribuídas à esse elemento, ou seja, esse componente contribui para elevar as diferenças salariais a favor dos homens, dada a existência de discriminação contra a mulher.

Analisando o ano 2000, existia uma diferença salarial de $\mathrm{R} \$ 1,30$ a favor dos homens. Com relação ao percentual relativo das desigualdades salariais, a parte das diferenças salariais explicada pelas variáveis de capital humano foram $-6,65 \%$, pela segmentação foram $-4,27 \%$, a parte não explicada e atribuída à discriminação correspondeu a 110,30\%, e a parte atribuída à interação correspondeu a $0,62 \%$. O conjunto total do componente explicado, composto pelas variáveis de capital humano e segmentação, não conseguiu esclarecer as diferenças salariais a favor dos homens, pois eram a favor das mulheres, sendo a maior parte explicada pela discriminação salarial contra as mulheres.

A diferença salarial entre homens e mulheres foi de, aproximadamente, 26,09\%, desses, $-1,53 \%$ foram atribuídos às variáveis de capital humano, $-0,98 \%$ à segmentação do mercado, 29,14\% à discriminação, e $0,14 \%$ à interação dos componentes. Dessa forma, nesse caso, as diferenças salariais tiveram uma queda na escala de $2,50 \%$, devido aos atributos de capital humano e segmentação a favor das mulheres. No entanto, a discriminação contribuiu para aumentar as diferenças na escala de $29,14 \%$, ou seja, foi responsável pela maior parte das diferenças salariais entre homens e mulheres. Se a remuneração das mulheres fosse ajustada 
ao nível dos homens, isto é, se não existisse discriminação, as mulheres teriam que ter um aumento salarial de $29,14 \%$.

No ano de 2007, existia uma diferença salarial de $\mathrm{R} \$ 1,45$ a favor dos homens. Com relação ao percentual relativo das desigualdades salariais, a parte das diferenças salariais explicada pelas variáveis de capital humano foi $-6,09 \%$, pela segmentação foi $-0,62 \%$, a parte não explicada e atribuída à discriminação correspondeu a $103,83 \%$, e a parte atribuída à interação correspondeu a 2,88\%. A parte atribuída ao capital humano e à segmentação não conseguiu explicar as diferenças salariais a favor dos homens, sendo a maior parte foi explicada pela discriminação salarial contra as mulheres.

A diferença salarial entre homens e mulheres foi cerca de $26,79 \%$, desses, $-1,43 \%$ foram atribuídos às variáveis de capital humano, $-0,15 \%$ à segmentação do mercado, cerca de $27,94 \%$ à discriminação, e $0,69 \%$ à interação dos componentes. Dessa forma, nesse caso, as diferenças salariais tiveram uma queda na escala de 1,58\%, devido aos atributos de capital humano e segmentação a favor das mulheres, no entanto, a discriminação contribuiu para aumentar as diferenças na escala de $27,94 \%$, ou seja, foi responsável pela maior parte das diferenças salariais. Se a remuneração das mulheres fosse ajustada ao nível dos homens, isto é, se não existisse discriminação, as mulheres teriam que ter um aumento salarial de $27,94 \%$.

Em relação ao ano de 2014, existia uma diferença salarial de $\mathrm{R} \$ 1,73$ a favor dos homens. Com relação ao percentual relativo das desigualdades salariais, a parte das diferenças salariais explicada pelas variáveis de capital humano foi $-8,78 \%$, pela segmentação foi $2,45 \%$, a parte não explicada e atribuída à discriminação correspondeu a 106,28\%, e a parte atribuída à interação correspondeu a 4,95\%. A parte atribuída ao capital humano e à segmentação não conseguiu explicar as diferenças salariais a favor dos homens, e a maior parte foi explicada pela discriminação salarial contra as mulheres.

A diferença salarial entre homens e mulheres foi de, aproximadamente, 24\%, desses, $1,87 \%$ foram atribuídos às variáveis de capital humano, $-0,53 \%$ à segmentação do mercado, cerca de $25,74 \%$ à discriminação, e $1,07 \%$ à interação dos componentes. Dessa forma, nesse caso, as diferenças salariais tiveram uma queda na escala de $2,39 \%$, devido aos atributos de capital humano e segmentação a favor das mulheres. No entanto, a discriminação contribuiu para aumentar as diferenças na escala de $25,74 \%$, ou seja, foi responsável pela maior parte das diferenças salariais. Se a remuneração das mulheres fosse ajustada ao nível dos homens, isto é, se não existisse discriminação, as mulheres teriam que ter um aumento salarial de $25,74 \%$.

Portanto, pode-se inferir que as diferenças salariais, a favor dos homens, para o mercado de trabalho do estado de Santa Catarina, em todo o período, foram explicadas, em grande parte, pela existência de discriminação contra as mulheres, já que as variáveis de capital humano e segmentação não conseguiram explicar as diferenças a favor dos homens, pois, na verdade contribuíram para redução das desigualdades salariais.

Em 2000, as diferenças salariais entre homens e mulheres estavam em torno de $26 \%$, em 2007 passam a representar, aproximadamente, 26,79\%, e em 2014 caem para cerca de $24 \%$. Portanto, pode-se afirmar que, no período analisado, houve redução das desigualdades salariais entre homens e mulheres.

No mesmo sentido, percebeu-se uma queda da parte atribuída à discriminação salarial. Portanto, pode-se afirmar que houve redução da discriminação salarial contra a mulher no 
período analisado no estado de Santa Catarina, contudo, mesmo as mulheres apresentando, em termos médios, atributos de capital humano superiores aos homens em alguns anos, elas recebiam, em média, menores remunerações devido à existência de discriminação salarial.

Com relação a decomposição das diferenças salariais, verificando o impacto percentual dos componentes nas diferenças salariais, percebeu-se que as variáveis de segmentação não foram representativas na sua contribuição. As variáveis de capital humano impactaram nas diferenças salariais em todo o período, no entanto, a favor das mulheres, contribuindo para reduzir as diferenças salariais, visto que as mulheres possuíam os melhores atributos. A discriminação foi a que teve maior contribuição na explicação das diferenças salariais em favor dos homens, pois aumentava as desigualdades em um grande percentual em todo o período.

Assim, a redução das desigualdades salariais entre homens e mulheres no período está relacionada fortemente com a queda da discriminação contra as mulheres, visto que o percentual atribuído ao capital humano e segmentação não teve grandes alterações no período.

Sendo assim, os resultados desse artigo estão em conformidade com os resultados encontrados por Baptista (2000), que mostrou que, mesmo as mulheres possuindo atributos produtivos, via capital humano ou segmentação, melhor que os homens, a discriminação é tão grande que reverte as vantagens às mulheres contribuindo para aumentar as vantagens salariais dos homens. Assim como os resultados encontrados por Silva e Kassouf (2000), que constataram elevada discriminação por gênero no mercado de trabalho brasileiro para o ano de 1995; e com os de Biderman e Guimarães (2002), que apontaram que o principal determinante das diferenças salariais que atingia as mulheres era a discriminação salarial. Estão em conformidade também com os resultados encontrados por Cirino (2008), que apontou que, mesmo as mulheres apresentando, em termos médios, atributos produtivos superiores aos dos homens, principalmente com relação à escolaridade, elas recebem menores salários médios por hora, confirmando a existência de discriminação; em conformidade com as afirmações apontadas por Tatei (2011), em que o efeito da discriminação se sobressai sobre os demais determinantes; e também com os resultados apontados por Fiuza-Moura (2015), que relatou que as diferenças salariais entre os sexos são causadas, em maior parte, por fatores discriminatórios.

Diante disso, pode-se afirmar que precisam ser desenvolvidas e implementadas políticas e ações voltadas para minimizar o problema da discriminação salarial contra a mulher, buscando, assim, diminuir as desigualdades salariais. Segundo Barros e Mendonça (1996), a existência de discriminação no mercado de trabalho pode gerar alguns problemas como: redução do grau de eficiência da alocação dos recursos; geração de conflitos nas relações trabalhistas; queda no grau de cooperação entre trabalhadores; queda da produtividade da economia; composição ineficiente da oferta de trabalho, e maior grau de pobreza.

Barros e Mendonça (1996) apontam que as leis contra a discriminação têm sido baseadas, fundamentalmente, em quatro elementos: igualdade de oportunidades; pagamento igual por trabalho igual; pagamento similar por trabalho equivalente; e discriminação inversa ou positiva. Dessa forma, uma ação que poderia ser implementada pelo Governo para reduzir a discriminação, seria a criação de comissões consultivas para fiscalizar os salários entre homens e mulheres que exercem trabalhos afins. Também poderiam ser criadas cotas de 
participação e cotas salariais para mulheres, promovendo tratamento diferenciado para quem recebe esse tratamento discriminatório do mercado. No entanto, essas ações possuem alguns problemas de operacionalização devido à dificuldade de conhecer a real produtividade dos trabalhadores e a realização de trabalhos iguais ou similares, além de ser socialmente questionável, combater discriminação com outra forma de discriminação. Apesar disso, essas ações poderiam surtir algum efeito no mercado de trabalho.

Além disso, é preciso maior conscientização dos empresários, contratantes e agenciadores de emprego, para que tenham conhecimento de todos os problemas que o tratamento diferenciado, baseado na discriminação, pode gerar para a sociedade como um todo, prejudicando a inserção das mulheres, contribuindo para manter o ciclo vicioso da pobreza, e desincentivando a mulher no mercado de trabalho.

Bohnenberger (2005) aponta que, mesmo a discriminação sendo uma prática proibida pela Constituição brasileira, ela ainda existe. Dessa forma, existir leis que proíbam essa prática é essencial, mas não é suficiente, pois a discriminação está inserida na cultura das pessoas. Segundo o autor $(2005$, p. 62) "para reverter essa situação, um bom começo é passar a falar abertamente sobre a discriminação, democratizando a questão, reconhecendo sua existência e tentando superar as práticas discriminatórias".

Outro fato que merece ser apontado, é que as mulheres também precisam contribuir para que essa realidade seja modificada. Elas precisam criar grupos de reinvindicação, organizando e lutando por seus direitos, tanto na esfera pública, como na esfera privada. A participação desses grupos na mobilização de melhores condições de trabalho é muito importante para a efetivação das políticas públicas. Nesse sentido, Bohnenberger $(2005$, p. 63) aponta que "é de suma importância que as mulheres e negros conheçam seus direitos, estejam presentes e atuantes nas organizações sindicais e se preparem para participar nas negociações coletivas [...] e também nos espaços institucionais para discussão de políticas públicas".

Portanto, a redução das desigualdades salariais entre homens e mulheres precisa ser pensada e efetivada por todos os atores econômicos e sociais, focando principalmente na redução da discriminação salarial, já que se mostrou o fator mais determinante das desigualdades.

\section{CONSIDERAÇÕES FINAIS}

Este artigo teve como objetivo geral explicar as diferenças salariais no mercado de trabalho do estado de Santa Catarina, nos anos 2000, 2007 e 2014, com base nas teorias que buscam explicar as desigualdades salariais.

As teorias que buscam explicar as desigualdades salariais utilizadas para explicação das diferenças salariais foram: capital humano, segmentação e discriminação. A teoria do capital humano busca explicação nas diferenças de escolaridade e experiência para a existência de diferenças salariais. Já a teoria da segmentação busca na segmentação do mercado explicação para a existência de diferenças salariais, e a teoria da discriminação busca explicação nas características pessoais dos trabalhadores a razão da existência de tais 
diferenças. Com relação à segmentação, neste trabalho, buscou-se nos setores e nos tipos de estabelecimento a explicação para a existência de tais diferenças, e com relação à discriminação, buscou-se no sexo do trabalhador a razão dos diferenciais de salários percebidos pelos trabalhadores.

Para atingir o objetivo deste trabalho foram formuladas equações Mincerianas para determinação dos salários, e decompostas as diferenças salariais pela decomposição de Oaxaca-Blinder. A decomposição verificou o impacto nas diferenças salariais atribuído ao capital humano e à segmentação. Dessa forma, a parcela não atribuída a esses dois componentes, foi caracterizada como discriminação salarial.

A decomposição de Oaxaca-Blinder para o mercado de trabalho do estado de Santa Catarina indicou que, em 2000, as diferenças salariais entre homens e mulheres estavam em torno de 26\%, em 2007 passam a representar, aproximadamente, 26,79\%, e em 2014 caem para cerca de $24 \%$. Portanto, afirmou-se que, no período analisado, houve redução das desigualdades salariais entre homens e mulheres. Além disso, percebeu-se uma queda da parte atribuída à discriminação salarial, logo, afirmou-se que houve redução da discriminação salarial contra a mulher no período analisado.

As diferenças salariais para o mercado de trabalho de Santa Catarina, no período analisado, foram explicadas, em grande parte, pela existência de discriminação contra a mulher, já que as variáveis de capital humano e segmentação não conseguiram explicar as diferenças a favor dos homens, pois, na verdade, contribuíram para diminuir as desigualdades.

A redução das desigualdades salariais entre homens e mulheres, em termos percentuais, verificadas no mercado de trabalho no período analisado, estão relacionadas fortemente com a queda da discriminação contra as mulheres, visto que o percentual atribuído ao capital humano e à segmentação foi pouco alterado. Os resultados encontrados, de queda da discriminação, nos três estados no período, estão em conformidade com os resultados encontrados por Bohnenberger (2005). Segundo o autor, entre os anos de 1992 e 2001, houve tendência de redução da discriminação salarial. Portanto, do período de 2007 a 2014, também se confirmou essa tendência. Ainda segundo o estudo de Bohnenberger (2005), a Região Sul do Brasil foi a região onde houve a maior queda da discriminação no período de seu estudo, se comparado com as demais regiões do Brasil.

Verifica-se neste estudo que as variáveis de segmentação pouco contribuíram para a explicação das diferenças salariais. Esse fato pode ser atribuído à forma como foi analisada a segmentação, uma vez que foi analisada a segmentação intrassetorial. Já as variáveis de capital humano contribuíram para impactar nas desigualdades salariais, no entanto, esse impacto muitas vezes foi no sentido de reduzir as diferenças, sendo essas explicadas, quase que totalmente, pela discriminação contra a mulher. As teorias do capital humano e da discriminação foram, portanto, as que mais impactaram na explicação das diferenças salariais, em conformidade com o que foi encontrado por Cirino (2008), apontando que o efeito do capital humano e o da discriminação foram importantes para explicar as diferenças salariais entre os sexos, sendo que o capital humano contribuía para reduzir as diferenças salariais e a discriminação para aumentá-las. Além disso, houve diferenças na explicação das desigualdades salariais dentro dos setores econômicos dos três estados no período analisado.

DRd - Desenvolvimento Regional em debate (ISSNe 2237-9029) 
As diferenças salariais, a favor dos homens, estavam mais relacionadas com a existência de discriminação do que com piores níveis de escolaridade das mulheres, ou com segmentação do mercado de trabalho. Isso pode ser corroborado pelo fato de as mulheres estarem avançando cada vez mais nos níveis de escolaridade, e até superando a escolaridade dos homens, no entanto, ainda assim, as suas remunerações permanecem inferiores às dos homens. Dessa forma, afirma-se que precisam ser desenvolvidas e implementadas políticas e ações voltadas para minimizar o problema da discriminação salarial contra a mulher, buscando assim, diminuir as desigualdades salariais.

Este trabalho avançou no aspecto de analisar as diferenças salariais nos anos 2000, 2007 e 2014, utilizando as teorias de capital humano, segmentação e discriminação para a explicação das diferenças salariais, comparando a evolução dessas desigualdades. No entanto, foram encontradas algumas limitações para a pesquisa. A principal foi em relação às variáveis de segmentação, devido ao baixo poder explicativo para as desigualdades salariais. Sugere-se que podem ser inseridas novas variáveis quando escolhidas outras bases de dados, ou ainda, que podem ser feita análise interssetorial, buscando melhorar a especificação e explicação das desigualdades salariais.

Além disso, cabe salientar que a parcela atribuída à discriminação contra a mulher é assim caracterizada como sendo aspectos não observados pelas variáveis do modelo, dessa forma, ao se incluir novas variáveis no modelo, esse percentual pode ser alterado. Ademais, como apontado por Baptista (2000) e Tatei (2011), na determinação dos salários também não levou-se em consideração alguns fatores importantes que podem interferir nos rendimentos, como a qualidade da educação, e as diferenças entre inserção e idade de jovens, adultos, casados e solteiros. Portanto, novas estimações podem tentar melhorar esses controles e aprimorar a determinação dos salários.

Este artigo não pretende esgotar a discussão a respeito do assunto, pois trata-se de um tema complexo, que envolve muitos determinantes. Sugere-se novos e complementares estudos a respeito do tema, podendo ser feita essa análise para outras regiões geográficas, outros setores, outros períodos, até mesmo para o Brasil como um todo.

\section{REFERÊNCIAS}

ARBACHE, J. S.. NEGRI, J. A. Diferenciais de salários interindustriais no Brasil: evidências e implicações. Texto para Discussão, Rio de Janeiro: IPEA, n. 918, nov. 2002. Disponível em: <http://repositorio.ipea.gov.br/handle/11058/2808>. Acesso em: 03 mar. 2016.

BAPTISTA, D. B. D. A. Diferenciais de rendimentos e discriminação por sexo no mercado de trabalho brasileiro na década de 90. In: ENCONTRO NACIONAL DA ASSOCIAÇÃO BRASILEIRA DE ESTUDOS POPULACIONAIS (ABEP); 12., Caxambu, Minas Gerais, 2000, Anais eletrônicos... Caxambu, Minas Gerais: ABEP, 2000. Disponível em: $<$ http://www.abep.nepo.unicamp.br/docs/anais/pdf/2000/Todos/Diferenciais\%20de\%20Rendi mento\%20e\%20Discrimina $\%$ C3\%A7\%C3\%A3o\%20por\%20sexo\%20no\%20Mercad.pdf $>$. Acesso em: 22 maio 2016. 
BARROS, R. P. de; MENDONÇA, R. Diferenças entre discriminação racial e por gênero e o desenho de políticas anti-discriminatórias. Revista Estudos Feministas, Florianópolis, v. 4, n. 1, p. 183-193, 1996.

; HENRIQUES, R.; MENDONÇA, R. Pelo fim das décadas perdidas: educação e desenvolvimento sustentado no Brasil. Texto para Discussão, Rio de Janeiro: IPEA, n. 857, jan. 2002. Disponível em: <http://repositorio.ipea.gov.br/handle/11058/2631>. Acesso em: 03 mar. 2016.

BECKER, G. S. Investment in human capital: A theoretical analysis. Journal of political economy, Chicago, v. 70, n. 5, p. 9-49, Oct. 1962. Disponível em: <http://www.jstor.org/ stable/1829103?seq=1\#page_scan_tab_contents $>$. Acesso em: $18 \mathrm{fev} .2016$.

BOHNENBERGER, R. Uma análise regional da discriminação de gênero e raça no mercado de trabalho brasileiro - 1992 a 2001. Dissertação (Mestrado em Economia de Empresas) - Universidade Católica de Brasília- UCB, Brasília, 2005.

BRASIL. Constituição (1988). Constituição: República Federativa do Brasil. Brasília, DF: Senado Federal do Brasil, 1988. Disponível em: $<$ http://www.planalto.gov.br/ccivil_03/ Constituicao/ConstituicaoCompilado.htm>. Acesso em: 16 maio 2016.

. Ministério do Trabalho e do Emprego. RAIS: Relação Anual de Informações Sociais. Disponível em: $<$ http://acesso.mte.gov.br/portal-mte/rais/\#2>. Acesso em: 16 maio 2016.

CARVALHO, A. P.; NERI, M. C.; SILVA, D. B. Diferenciais de salários por raça e gênero: aplicação dos procedimentos de Oaxaca e Heckman em pesquisas amostrais complexas. Revista Ensaios Econômicos, Rio de Janeiro: FGV, n. 638, dez. 2006. Disponível em: $<$ https://core.ac.uk/download/files/153/6753094.pdf >. Acesso em: 21 mar. 2016.

CHAVES, A. L. L. Estimativa da discriminação salarial, por gênero, para os trabalhadores assalariados da Região Metropolitana de Porto Alegre. Revista Mulher e Trabalho, Porto Alegre, v. 2, p. 85-94, 2011.

CIRINO, J. F. Participação feminina e rendimento no mercado de trabalho: análise da decomposição para o Brasil e as regiões metropolitanas de Belo Horizonte e Salvador. Tese (Doutorado Doctor Scientiae em Economia Aplicada) - Universidade Federal de Viçosa, Viçosa, 2008. Disponível em: <http://www.locus.ufv.br/handle/123456789/111>. Acesso em: 09 mar. 2016.

FERNANDES, R. Desigualdade salarial: aspectos teóricos. Rio de Janeiro: Ipea, p.1-50, out. 2002. Disponível em: <https:/www.en.ipea.gov.br/agencia/images/stories/PDFs/livros/ capitulo1_desigualdade.pdf $>$ Acesso em: 03 mar. 2016.

FERREIRA, F. H. G. et al. Análise e queda da desigualdade de renda no Brasil: uma atualização para 2005. In: BARROS, Ricardo Paes de. (Org.); FOGUEL, Miguel Nathan (Org); ULYSSEA, Gabriel (Org.). Desigualdade de Renda no Brasil: uma análise da queda recente. Brasília: IPEA, v. 1, 2006, p. 359-378. 
FIUZA-MOURA, F. K. Diferenciais de salários na indústria brasileira por sexo, cor e intensidade tecnológica. $100 \mathrm{f}$. Dissertação (Mestrado em Economia Regional) Universidade Estadual de Londrina - UEL, Centro de Estudos Sociais Aplicados, Londrina, 2015.

IPEA (Instituto de Pesquisa Econômica Aplicada). IPEADATA. Disponível em: $<\mathrm{http}: / / w w w . i p e a d a t a . g o v . b r />$. Acesso em: 17 maio 2016.

JACINTO, P. A. Diferenciais de salários por gênero na indústria avícola da Região Sul do Brasil: uma análise com micro dados. Revista de Economia e Sociologia Rural, Brasília, v. 43 , n. 3, p. 529-555, jul./set. 2005.

JANN, B. A Stata implementation of the Blinder-Oaxaca decomposition. Stata Journal, ETH Zurich Sociology Working Paper, v. 8, n. 4, p. 453-479, maio. 2008.

LIMA, R. Mercado de trabalho: o capital humano e a teoria da segmentação. Revista Pesquisa e Planejamento Econômico, Rio de Janeiro, v. 10, n. 1, p- 217-272, abr. 1980.

LOUREIRO, P. R. A. Uma resenha teórica e empírica sobre economia da discriminação. Revista Brasileira de Economia, Rio de Janeiro, v. 57, n. 1, p. 125-157, jan./mar. 2003.

MARGONATO, R. C. G. Diferenciais de rendimentos do trabalho feminino nos setores econômicos da Região Sul do Brasil. 96 f. Dissertação (Mestrado em Economia Regional) Universidade Estadual de Londrina - UEL, Centro de Estudos Sociais Aplicados, Londrina, 2011.

OAXACA, R. Male-female wage differentials in urban labor markets. International economic review, Pennsylvania, v. 14, n. 3, p. 693-709, Oct. 1973.

RAMOS, L.; VIEIRA, M. L. Desigualdade de rendimentos no Brasil nas décadas de 80 e 90: evolução e principais determinantes. Texto para Discussão, Rio de Janeiro: IPEA, n. 803, jun. 2001. Disponível em: <http://repositorio.ipea.gov.br/handle/11058/1979>. Acesso em 26 fev. 2016.

ROCHA, R. C. B.; PERO, V. Discriminação racial e educação no Brasil. Revista Sinais Sociais, Rio de Janeiro, v. 1, n. 33, p. 122-155, abr. 2007.

SATEL, C. I. R. Desigualdade de rendimentos do trabalho no Paraná no período 2002 a 2009: uma análise quantílica para o quartil $0,25^{\circ}$ e percentil $0,90^{\circ}$ da distribuição de rendimentos. 118 f. Dissertação (Mestrado em Economia Regional) -Universidade Estadual de Londrina- UEL, Centro de Estudos Sociais Aplicados, Londrina, 2011.

SCHULTZ, T. W. Investment in human capital. The American Economic Review, Pittsburgh, v. 51, n. 1, p. 1-17, Mar. 1961.

SILVA, N. de D. V.; KASSOUF, A. L. Mercados de trabalho formal e informal: Uma análise da discriminação e da segmentação. Revista Nova Economia, Belo Horizonte, v. 10, n. 1, p. 40-71, jul. 2000. 
TATEI, F. Desigualdades no mercado de trabalho da América Latina: a discriminação por sexo entre os trabalhadores com ensino superior no Brasil e no México. Dissertação (Mestrado em Integração da América Latina) - Universidade de São Paulo- USP, São Paulo, 2011.

YANNOULAS, S. C. Dossiê: Políticas públicas e relações de gênero no mercado de trabalho. Brasília: CFEMEA - Centro Feminista de Estudos e Assessoria; FIG, nov. 2002. Disponível em: $<$ https://www.nescon.medicina.ufmg.br/biblioteca/imagem/2043.pdf $>$. Acesso em: 19 fev. 2016.

Artigo recebido em: 19/04/2017

Artigo aprovado em: 16/10/2017 